\title{
Maternal behavior toward premature twins: implications for development
}

\author{
Barbara M Ostfeld ${ }^{1}$, Richard H Smith ${ }^{2}$, Mark Hiatt ${ }^{1}$ and Thomas Hegyi ${ }^{1}$ \\ ${ }^{1}$ Division of Neonatology, UMDNJ-Robert Wood Johnson Medical School, St Peter's University Hospital, New \\ Brunswick, NJ \\ ${ }^{2}$ (Retired) Department of Psychiatry, McLean Hospital, Harvard Medical School, Belmont, MA
}

\begin{abstract}
Assisted reproductive techniques and fertility enhancing therapies have increased multiple births and, ther efore, the risk of prematurity and its developmental consequences. Parent intervention is an effective source of compensation for the cognitive effects of prematurity. We hypothesized that relative to parents of preterm singletons, parents of preterm twins are less able to provide such enhancing care, resulting in a developmental disadvantage for preterm twins. Maternal-infant interactions of premature singletons $(n=22$; birth weight $=1668 \pm 350$ g, gestational age $=32.3$ \pm 2.1 weeks $)$ and premature twins $(n=8$; birth weight $=1618 \pm 249$ g; gestational age $=32.0$ \pm 2.6 weeks) with comparable demographic and medical status were observed at home at 1 and 8 months corrected age using a $30 \mathrm{~min}$ checklist of developmentally facilitative behavior. Mental (MDI) and psychomotor (PDI) indices of the Bayley Scales of Infant Development and Caldwell Home Observations for Measurement of the Environment (HOME) inventories were administered (18 months corrected age). Compared with mothers of premature singl etons, mothers of premature twins exhibited fewer initiatives $(P<0.001)$ and responses $(P<0.01)$ and were less responsive to positive signals $(P<0.01)$ and crying $(P<0.01)$. Unprompted by the infant, twin mothers lifted or held $(P<0.05)$, touched $(P<0.01)$, patted $(P<0.05)$ or talked $(P<0.01)$ less. Singleton MDIs surpassed twins $(119.4 \pm 7.7$ vs $103.6 \pm 7.7 ; \mathrm{P}<0.01)$. Maternal verbal behavior and the acceptance of child factor (HOME), both favoring singletons, correlated with MDI (R-square = $0.46, P<0.0002)$. Mothers of premature twins exhibited fewer initiatives and responses toward offspring than did mothers of premature singletons. Maternal behavior was predictive of cognitive development. Twin Research (2000) 3, 234-241.
\end{abstract}

Keywords: multiple birth, prematurity, maternal-infant interaction, cognitive development

\section{Introduction}

Assisted reproductive techniques and fertility enhancing therapies have increased multiple births, placing infants at greater risk for prematurity ${ }^{1}$ and its effects upon cognitive development. Parent-infant interaction has proved to be an effective modality for enhancing cognitive development. ${ }^{2-10}$ How ever, parents of twins are less likely than parents of singletons to exhibit linguistic and interactive behavior that facilitates language and cognition. ${ }^{11-18}$ The behavior of parents of twins may be attributable to greater child care burdens ${ }^{19,20}$ and el evated anxiety and depression, ${ }^{19,21}$ risk factors for diminished parental sensitivity, stimulation and responsiveness. ${ }^{22-24}$ When infants are a product of prematurity as well as multiple birth, parents may experience

Correspondence: Dr BM Ostfeld, St Peter's University Hospital, 254 Easton Avenue, New Brunswick, NJ08903, USA. Tel: (732) 745 8523; Fax: (732) 2496306; E-mail: barbostfeld @aol.com Received 31 January 2000; revised 4 May 2000; accepted 4 May 2000 incremental anxiety secondary to additional emotional burdens and care requirements associated with low birth weight, ${ }^{25-28}$ thus putting these infants at even greater risk of receiving diminished parental stimulation.

Between 1991 and 1994, twins constituted one fifth of the admissions to neonatal intensive care units (NICUs) in the Neonatal Research Network. ${ }^{29}$ With twin births increasing and $53 \%$ of these born prematurely, ${ }^{1}$ this proportion is expected to rise. Survival of preterm twins has also increased, ${ }^{30}$ resulting in a need to understand better the factors that affect the development of this growing segment of high risk births. Previous studies of parent stimulation and cognitive development have failed to match premature twins with comparable singletons, ${ }^{13,18}$ making it difficult to assess risk factors and outcomes relevant to the premature twin. In the absence of such data, neonatal follow-up or intervention studies vary as to whether they identify inclusion criteria for multiple births, indicate the proportion of multiple births in their cohorts or report outcomes specific to this subgroup..$^{6,8,9,31-37}$ 
We undertook this study to address limitations in information currently available about parenting differences between premature singletons and premature twins and the effects of such parental behavior on development. We hypothesized that in light of the dual stress of prematurity and multiple infants, maternal interactions with premature infant twins would differ from those of mothers of premature singletons of comparable biological and social risk and that these differences would be correlated with lower scores for cognitive development in preterm twins relative to preterm singl etons. If parenting behavior is confirmed as a risk factor for premature twin development, then compensatory interventions and support services that are offered spontaneously for rarer but more publicized cases of higher order multiples ${ }^{38}$ could become the standard of care for families of premature twins as well.

\section{Methods}

\section{Study population}

Patients admitted to a Level III NICU were prospectively enrolled in a longitudinal study to assess developmental outcome if they met the following criteria: gestational age between 27 and 34 weeks, maternal age between 18 and 40 years of age, absence of intraventricular hemorrhage, seizures and genetic anomalies. Informed consent was obtained.

The subgroup that comprised the post hoc analysis of the present study consisted of all subjects whose parents had been randomized to a hospital-based psychosocial intervention to:

(1) receive information about the premature infant's facial cues and techniques of infant massage;

(2) attend meetings with a nurse practitioner to discuss their adjustment to the premature birth;

(3) view a videotape of peer support featuring parents of discharged premature infants.

Thirty-three infants (10 twins and 23 singletons) were entered into the intervention group. One set of twins was lost to follow-up after the family moved away and one singleton was disqualified due to an abnormal neurological finding, resulting in a longitudinally followed group of 8 twins and 22 singletons. Socioeconomic status was evaluated using the Hollingshead two-factor Index of Social Position. ${ }^{39}$ Birth weight, gestational age, five minute Apgar, length of stay, medical complications, gender and maternal and paternal ages were recorded. In addition, intention to breastfeed was al so recorded before discharge.

\section{Procedure}

The Brazelton Neonatal Behavioral Assessment Scal $e^{40}$ was administered when the infant reached term age. Two home observations were scheduled, at 1 (Time 1) and 8 (Time 2) months corrected age. Two examiners blind to the hypotheses were trained to reliability. For each home visit to singletons, these examiners alternated conducting a 30 min observation of mother and infant using a modification of the Beckwith Mother-Infant Behavior Checklist ${ }^{41,42}$ For twins, both of these examiners conducted the evaluation jointly, each coding one infant and the mother's activities with that infant. Mothers were instructed to try to maintain normal activities and behavior. At 18 months corrected age, the Mental and Psychomotor Development Indices (MDI; PDI) of the Bayley Scales of Infant Development ${ }^{43}$ and the Caldwell HOME Scal $e^{44}$ were administered.

\section{Measures}

The postnatal factors form The medical risk index of the first month scores for the presence of feeding in the first 48 hours and the absence of respiratory distress, positive or suspected infection, ventilatory assistance, non-infectious illness or anomaly, metabolic disturbance, seizure, hyperbilirubinemia or exchange transfusion, temperature disturbance and surgery. ${ }^{45}$ The scaled score has a mean of 100 and a standard deviation of 20 . Higher scores indicate lower risk.

The HOME inventory (home observation for measurement of the environment) This semi-structured interview and observation tool ${ }^{44}$ measures the quality of the home and family environment as characterized by parental behavior and material resources. There are six factors or subscales: I, Emotional and Verbal Responsivity; II, Acceptance of Child (by the parent); III, Organization of the Environment; IV, (Appropriate) Play Materials; V, Parental Involvement and VI, Opportunities for Variety (in daily stimulation). Subscale VI included activities deemed beyond the scope of this study. Raw scores, the sum of the positive (desirable) findings, are derived from questions and/or observations.

Brazelton neonatal behavioral assessment scale Items in this measurement of behavioral organization $^{40}$ may be combined into clusters measuring habituation, orientation, motor function, range of state, regulation of state and autonomic stability. ${ }^{46}$ Habituation is the sum of the habituation scores to a light, a rattle, a bell or focal pressure on the heel. Scores for each habituation test range from 1, failure to habituate, to 9 , rapid habituation. 
Modified Beckwith mother-infant behavior checklis$\mathrm{t}$ In a 30 min observation, ${ }^{41,42}$ maternal behavior toward infants are scored every 15 s, yielding 120 potential occurrences per item of behavior. Behavior is coded as unprompted (initiating) or responsive, depending upon whether it occurs before or after an infant's behavior. Maternal behavior includes picking-up/holding, affectionate touches, patting and rocking, positive verbalization, play noise, toy stimulation. Infant behavior includes non-distress verbalizations, reaching, eye contact, smiles (total infant activity). More than one category of behavior can be scored per episode. For each episode, the infant's state of arousal (deep sleep, light sleep, drowsy, alert, active, crying) is recorded as is the following non-distress initiating or responding behavior: vocalization, approach, mutual gaze, smile. The total score for infant behavior is the sum of these activities.

\section{Statistical methods}

Two-tailed t tests were used to compare singleton and twin groups on demographic, medical, Time 2 infant behavior, HOME inventory factors and developmental data and Twin A and Twin B on demographic, medical and developmental data. Kolmogorov-Smirnov two-sample, $\chi^{2}$ or Fisher exact tests were used for categorical data. State of consciousness in singletons and twins during observation Time 1 and observation Time 2 were compared using a two-way analysis of variance in which time was a repeated measure (within-subject) variable and group (singleton vs twin) a between-subjects variable. Maternal behavior and total infant activity were also measured in this manner. Categorical maternal behavior in the singleton and twin groups was evaluated by $\chi^{2}$ or Fisher exact tests. A forward stepwise multiple regression analysis was used to determine the best predictors of cognitive development. The alpha level was set at 0.05 for all anal yses.

\section{Results}

As noted in Table 1, the demographic and medical characteristics of the singleton and twin groups were comparable with respect to birth weight, 5 min Apgar score, medical complications, length of stay and the Brazelton Scale habituation cluster. Nor were statistical differences between groups noted for gender or feeding modality. One set of twins consisted of a male and female, one of two males and two of two females, resulting in a distribution of three males and five females among the twins compared with 10 males and 12 females among the
Table 1 Characteristics of twins and singletons

\begin{tabular}{lcc}
\hline & Singleton group & Twin group \\
$\mathrm{n}$ & 22 & 8 \\
\hline Birth weight (gm) & $1668 \pm 350$ & $1618 \pm 249$ \\
$5^{\prime}$ Apgar & $8.4 \pm 0.8$ & $8.0 \pm 0.8$ \\
Medical complication index ${ }^{a}$ & $77.7 \pm 11.1$ & $79.8 \pm 17.4$ \\
Length of stay (weeks) & $4.0 \pm 1.8$ & $3.6 \pm 1.1$ \\
Brazel ton scal e cluster I & $21.8 \pm 6.2$ & $20.4 \pm 6.8$ \\
(habituation) & & \\
\hline
\end{tabular}

Note: data $=$ means \pm standard deviations; ${ }^{\text {apostnatal factors form. }}$.

singletons. Maternal intent to breastfeed was noted for six of eight twins and 16 of 22 singletons. No significant differences between singleton and twin families were obtained on demographic variables (Table 2) or 18 month corrected age home environments assessed by comparing the 22 singl eton homes with the four twin homes on the HOME subscal es III, organization of the environment and IV, play materials. Twin A and twin B had comparable medical and developmental status (Table 3 ).

Arousal states were compared for twins and singletons at observation Times 1 and 2 (Table 4). The alert state, equally prevalent and predominant in both groups, doubled to 28 of the $30 \mathrm{~min}$ by the second visit $(P<0.001)$. The active and crying states were infrequent in both groups and diminished over time. How ever, at Time 1, twins were more likely to exhibit these states $(P<0.05)$.

Positive maternal behavior was evaluated over both visits (Table 5). Unprompted by the infant, mothers of singletons were more likely to pick up, $(P$ $<0.05)$ touch $(P<0.01)$, pat and rock $(P<0.05)$ or

Table 2 Characteristics of parents of twins and singletons

\begin{tabular}{|c|c|c|}
\hline n (families) & $\begin{array}{l}\text { Singleton group } \\
22\end{array}$ & $\begin{array}{l}\text { Twin group } \\
4\end{array}$ \\
\hline Socio-economic level ${ }^{a}$ & $3.3 \pm 0.9$ & $3.3 \pm 1.2$ \\
\hline Maternal age (years) & $26.6 \pm 5.5$ & $29.3 \pm 5.6$ \\
\hline Paternal age (years) & $29.5 \pm 8.1$ & $30.0 \pm 6.1$ \\
\hline Duration of pregnancy (w eeks) & $32.3 \pm 2.2$ & $32.0 \pm 2.6$ \\
\hline
\end{tabular}

Note: data $=$ means \pm standard deviations; ${ }^{\text {a } 1 ~=~ h i g h e s t, ~} 5=$ lowest (Hollingshead Two-factor Index of Social Position).

Table 3 Comparability of twin A and twin B

\begin{tabular}{lcc}
\hline & Twin A $(\mathrm{n}=4)$ & Twin B $(\mathrm{n}=4)$ \\
\hline Birth weight (gm) & $1618 \pm 281$ & $1620 \pm 256$ \\
5' Apgar $^{\prime}$ edical complication index & $7.8 \pm 0.5$ & $8.3 \pm 0.9$ \\
Bayley Scal es & $81.3 \pm 15.3$ & $78.3 \pm 21.7$ \\
Mental development index & $101.8 \pm 8.7$ & $105.5 \pm 7.3$ \\
(18 months corrected age) & & \\
Bayley Scal es & $111.0 \pm 10.4$ & $108.3 \pm 10.1$ \\
Psychomotor development & & \\
index (18 months corrected age) & & \\
\hline
\end{tabular}

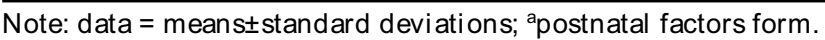


Table 4 States of consciousness in premature twins and singletons at 1 and 8 months corrected age

\begin{tabular}{|c|c|c|c|c|c|c|c|}
\hline \multirow[b]{2}{*}{ State } & \multicolumn{2}{|c|}{ Observation time 1} & \multicolumn{2}{|c|}{ Observation time 2} & \multicolumn{3}{|c|}{$P$ values ${ }^{*}<0.05^{* *}<0.01 * * *<0.001$} \\
\hline & Singleton group & Twin group & Singleton group & Twin group & Group (G) & Times $(T)$ & $\mathrm{G} \times \mathrm{T}$ \\
\hline Deep sleep & $0.3 \pm 0.9$ & $2.0 \pm 5.3$ & 0 & 0 & & * & \\
\hline Light sleep & $18.1 \pm 21.6$ & $19.1 \pm 33.4$ & 0 & 0 & & ** & \\
\hline Drowsy & $34.4 \pm 23.7$ & $15.6 \pm 22.2$ & $0.2 \pm 0.6$ & 0 & & *** & \\
\hline Alert & $58.6 \pm 36.2$ & $64.5 \pm 45.5$ & $116.3 \pm 5.1$ & $110.3 \pm 8.1$ & & *** & \\
\hline Active & $4.9 \pm 4.7$ & $8.9 \pm 10.9$ & $3.0 \pm 4.5$ & $7.1 \pm 5.9$ & * & & \\
\hline Cry & $4.2 \pm 9.2$ & $10.1 \pm 11.3$ & $1.0 \pm 1.5$ & $2.6 \pm 2.9$ & * & * & \\
\hline
\end{tabular}

Note: For each state a group (singleton, $n=22$, vs twin, $n=8) \times$ time ( 1 vs 8 months post hospital discharge) analysis of variance was conducted in which time was a repeated measures (within-subject) variable and group was a between-subjects variable; data=means \pm standard deviations; data derived by scoring state every $15 \mathrm{~s}$ for a $30 \mathrm{~min}$ period for a total of 120 scores per subject.

Table 5 Positive maternal behavior toward premature twins and singletons at 1 and 8 months corrected age

\begin{tabular}{|c|c|c|c|c|c|c|c|}
\hline \multirow[b]{2}{*}{ Maternal behavior } & $\begin{array}{l}\text { Observati } \\
(n=22) \\
\text { Singleton }\end{array}$ & $\begin{array}{l}\text { me } 1 \\
(n=8) \\
\text { Twin }\end{array}$ & $\begin{array}{l}\text { Observa } \\
(n=22) \\
\text { Singleton }\end{array}$ & $\begin{array}{l}\text { ne } 2 \\
(n=8) \\
\text { Twin }\end{array}$ & \multicolumn{3}{|c|}{$\begin{array}{l}\text { P values for } F:{ }^{*}<0.05 \\
{ }^{* *}<0.01 * * *<0.001\end{array}$} \\
\hline & group & group & group & group & Group (G) & Times $(T)$ & $\mathrm{G} \times \mathrm{T}$ \\
\hline 1. Pick up: unprompted & $95.5 \pm 41.7$ & $58.8 \pm 30.9$ & $24.7 \pm 28.6$ & $14.0 \pm 16.0$ & * & $* * *$ & \\
\hline 2. Touch: unprompted & $21.1 \pm 17.8$ & $3.8 \pm 3.5$ & $7.7 \pm 6.0$ & $1.4 \pm 1.8$ & ** & * & \\
\hline 3. Pat, rock: unprompted & $20.9 \pm 19.0$ & $8.0 \pm 6.6$ & $1.6 \pm 3.3$ & $0.1 \pm 0.4$ & * & *** & \\
\hline 4. Talk: unprompted & $21.8 \pm 12.9$ & $8.5 \pm 5.5$ & $17.7 \pm 12.5$ & $6.1 \pm 5.3$ & ** & & \\
\hline 5. Touch: response to positive signal & $3.3 \pm 6.6$ & $0.4 \pm 1.1$ & $3.1 \pm 3.6$ & $0.1 \pm 0.4$ & & & \\
\hline 6. Talk: response to positive signal & $20.8 \pm 16.8$ & $8.1 \pm 5.9$ & $23.8 \pm 14.5$ & $5.0 \pm 4.3$ & ** & & \\
\hline 7. Total maternal initiatives & $171.0 \pm 58.4$ & $84.3 \pm 42.5$ & $68.6 \pm 37.1$ & $47.9 \pm 28.4$ & *** & *** & ** \\
\hline 8. Total maternal responses & $28.0 \pm 23.8$ & $12.4 \pm 10.9$ & $37.6 \pm 23.3$ & $6.9 \pm 6.1$ & ** & & \\
\hline
\end{tabular}

Note: For each maternal behavior a group (singleton vs twin) $\times$ time (1 vs 8 months post hospital discharge) analysis of variance was conducted in which time was a repeated measures (within-subject) variable and group was a between subjects variable; data=means and standard deviations derived by scoring each maternal behavior every 15 s for a 30min observation period, yielding a maximum score of 120

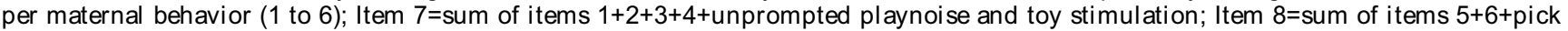
ups, pats \& rocks, playnoises and toy stimulation in response to positive signal.

talk to $(P<0.01)$ their infants. Although such behavior patterns were less frequent in both groups at Time 2, they remained more prevalent in the singleton group. Unprompted maternal talking was also more prevalent in the singleton group ( $P<$ 0.01 ), but unlike the previously noted forms of behavior, each group sustained its performance levels over time.

Responsive maternal behavior followed a positive infant signal. Responsive touch, infrequent at Times 1 and 2, was comparable for both groups. However, responsive talking was more common tow ard singletons $(P<0.01)$. This behavior did not diminish in either group, and the favourable score of the singleton group was sustained.

Maternal response to negative stimulation was assessed by evaluating reaction to crying. Ten singletons and six twins had crying episodes for $30 \mathrm{~s}$ or longer. Maternal responses were scored as positive if they occurred within 30 seconds. Singleton crying was less likely to be ignored. Eighty percent of the singletons but no twin received a response $(P<$ 0.01 ). By the second visit, seven singletons and five twins qualified for attention. Seventy percent of the singl etons and $40 \%$ of the twins received a response, a difference that was not significant.

On the three HOME inventory factors associated with parental behavior toward an individual child, singletons experienced more advantageous interactions than did twins on subscal es II, acceptance of child $(5.7 \pm 2.2$, vs $3.8 \pm 2.3, \mathrm{P}<.05)$ and $\mathrm{V}$, maternal involvement with the child, $(4.7 \pm 1.7$ vs $2.8 \pm 1.2, \mathrm{P}<0.01)$. There was no difference between groups on Factor I, emotional and verbal responsivity.

Twins exhibited less total activity than did singletons $(P<0.001)$. The difference between groups was based on a markedly increased activity level for singletons at Time 2 that was not mirrored by increases in twin activity. At Time 1, singletons and twins exhibited similar total activity levels (63.5 \pm 3.3 vs $43.4 \pm 29.4)$. By Time 2 , singletons surpassed twins (90.2 \pm 31.8 vs $32.5 \pm 17.9, \mathrm{P}<0.0001)$. During this visit, singletons smiled more at mother $(16.1 \pm 12.3$ vs $3.5 \pm 3.7, P<0.01)$ and engaged in more mutual gazing $(31.3 \pm 15.8$ vs $16.5 \pm 6.3$.

Although both singletons and twins performed within normal limits on the MDI and PDI, singletons scored higher than twins on the MDI $(P<0.01)$ 
(Figure 1). Maternal verbal initiatives (unprompted talking) at Time 2, Subscal e II, acceptance of child, of the HOME inventory at 18 months corrected age and Brazelton cluster I (habituation) were correlated with the MDI (Table 6) as determined by stepwise forward multiple regression. As noted earlier, the first two variables were more evident in singleton families, whilst habituation scores were comparable between groups. The analysis yielded an adjusted R-square of $0.46(P<0.001)$, with maternal verbal behavior and the avoidance of punishment subscale accounting for the significance.

\section{Discussion}

The frequency and quality of maternal behavior toward premature twin infants differed from that of mothers of premature singletons of comparable biological and social risk, and these differences were

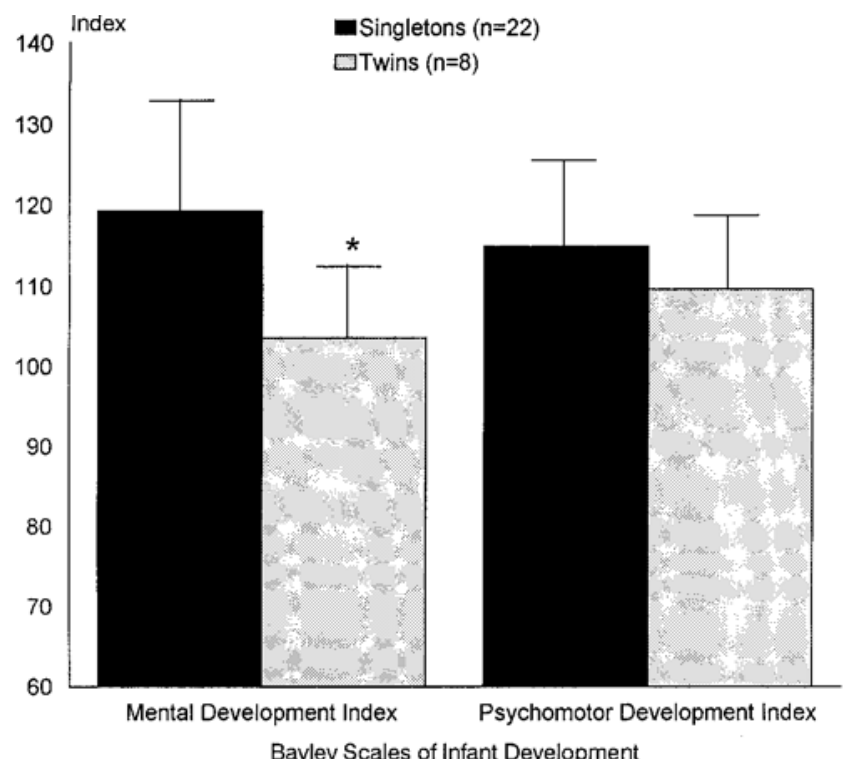

Figure 1 Developmental outcome of premature twins and singletons at 18 months corrected age, ${ }^{*} \mathrm{P}<0.05$

Table 6 Regression analysis for 18 month corrected age mental development index of the Bayley Scales of infant development

\begin{tabular}{llll}
\hline Variables & $\begin{array}{l}\text { Multiple } \\
\text { R-square }\end{array}$ & $\begin{array}{l}\text { R-square } \\
\text { change }\end{array}$ & P-level \\
\hline $\begin{array}{l}\text { Maternal talking: } \\
\quad \text { unprompted (time 2) }\end{array}$ & 0.31 & 0.31 & 0.002 \\
$\begin{array}{l}\text { HOME factor II: } \\
\text { acceptance of child }\end{array}$ & 0.46 & 0.15 & 0.01 \\
Brazel ton habituation cluster & 0.51 & 0.06 & 0.09 \\
\hline
\end{tabular}

Note: $F(3,26)=9.14, \quad p<0.001 ;$ adjusted R-square=0.46; aHome Observation for Measurement of the Environment. correlated with lower cognitive development in the premature twins at 18 months corrected age. Mothers of premature singletons initiated more positive behavior and responded to their infant's signals more frequently than did mothers of premature twins. Although IQ at 18 months corrected age was in the normal range for all infants, mean IQ was significantly higher in the singleton group than in the twin group.

The variance we obtained in developmental outcome was associated with the frequency of maternal verbal initiatives at 8 months corrected age and portions of the HOME inventory, each of which has been found elsewhere to be predictive of cognitive development. ${ }^{11,18,31,47-49}$ A favorable score on the acceptance of child factor of the HOME is consistent with the developmentally facilitative maternal qualities Wilson ${ }^{49}$ found to be positively associated with intellectual development in subjects in the Louisville Twin Study. Finally, while Bornstein and Ruddy ${ }^{11}$ had found an association between habituation and cognitive outcome, we did not, possibly because our assessment was conducted at term age, 4 months earlier than theirs.

With respect to infant behavior, twins and singletons initially had comparable activity levels. ${ }^{11,17}$ However, the similarity was not sustained because twin activity level did not increase as much as that of singletons. By 8 months corrected age, perhaps in response to differences in parenting behavior, twins exchanged significantly fewer smiles and mutual gazes with their mothers, a finding consistent with changes observed el sewhere ${ }^{12}$ and one less likely to reinforce parental initiatives.

Twins, who constitute $95 \%$ of all multiple births, are seven times more likely than singletons to be premature and are also more likely to experience higher rates of morbidity and mortality. ${ }^{1}$ Many mediators of these differences have been identified. For example, when studies control for biological risks such as lower gestational ages or birth weights, twins and singletons have similar survival ${ }^{30}$ and morbidity. ${ }^{29,50}$ When social risk factors are also controlled, they have similar long term IQs, as well. ${ }^{51,52}$ Researchers have also attributed a portion of the variance in specific cognitive skills of twins to diminished parental stimulation, ${ }^{13,18,53,54}$ a finding we confirmed for premature twins.

Our results are consistent with other studies on the characteristics and effects of parenting behavior toward twins. ${ }^{11-14,18,49,53}$ Bornstein and Ruddy ${ }^{11}$ studied full-term singletons and full-term heal thy twin infants and obtained differences between mothers of singletons and twins that affected developmental outcomes. Singleton mothers more frequently drew their infant's attention to the environment, and mothers who did so had infants 
with better language development. By limiting our cohort to premature twins and comparable controls, we studied a population that is at increased risk for developmental problems and addressed a methodologic limitation of some studies. For example, like Bornstein and Ruddy, ${ }^{11}$ Conway et $\mathrm{al}^{13}$ and Tomasello et al ${ }^{18}$ found more developmentally facilitative maternal behavior in singletons than in twins, but these results were confounded by differences in gestational age between the groups. Specifically, the twin subjects were also more likely to be premature.

By limiting the study to premature infants with comparable medical and social risk factors, we were able to assess if the incremental stress of a multiple birth has an effect on parental behavior in an al ready challenging child rearing situation. Parents of premature infants have an increased risk of being depressed and anxious, ${ }^{25,27}$ emotional states that could constrict sensitive interactions ${ }^{22-24,55}$ for either singleton or twin mothers and thus attenuate behavioral differences between their offspring. On the other hand, it has al so been reported that parents of premature infants increase their initiatives, providing compensatory although not necessarily more sensitive stimulation. ${ }^{56}$ This effect could al so serve to attenuate behavioral differences between parents of premature singletons and twins. Goldberg et al ${ }^{57}$ compared premature singletons and premature twins during infancy. Using maternal behavior comparable to those we studied, they assessed the outcome variable of attachment security. Twins and singletons were comparable in attachment security, suggesting that maternal behavior was similar between groups. However, maternal behavior specific to twins and singletons was not presented, nor were cognitive or language outcomes determined. Our results indicate that twin status does alter maternal behavior toward a premature cohort.

A major limitation of this study is the twin sample size. Neverthel ess, the homogeneity between groups on the medical, psychomotor, social and environmental variables allows for valid comparisons. Another limitation of this study is that follow-up was confined to 18 months corrected age. Differences in IQ between premature twins and singletons can resolve by school age. ${ }^{51}$ For premature infants in general, cognitive outcomes after age 5 are more likely to be associated with the home environment than with perinatal risk factors. ${ }^{58} \mathrm{~A}$ larger study with more matched subjects and a longer study period is indicated. Such studies should also include an analysis of potential demographic interaction effects, assessment of parental depression and stress and a measure of language devel opment, an outcome variable sensitive to the effects of twin childrearing. ${ }^{18}$
Our findings have important implications in two areas. First they reinforce the need to reconsider how premature twin data is treated in neonatal outcome and intervention studies, particularly when the outcome measures include parental behavior that is influenced by plurality. Currently, there is a variance in whether twins are identified and how much data is provided even when their presence is noted. While some studies that have identified twins in their cohorts also indicate what proportion of the sample they represent and how the variable is treated statistically, 33,59 others only indicate the inclusion criteria. ${ }^{31,60}$

Secondly, it has been reported that twin mothers provide more stimulation to their two babies, in sum, than mothers of singletons. ${ }^{11}$ Their inability to provide an individual twin with stimulation comparable to that of a singleton underscores the need for additional support and intervention services. Yet twins receive significantly less community assistance than do rarer higher order multiples. ${ }^{38} \mathrm{We}$ need to continue to define the challenges facing parents of preterm twins so that appropriate interventions can be developed.

\section{Acknowledgements}

This work was supported by a grant from the National Institute of Mental Health (R01 MH 34060) to Dr Ostfeld. The paper was presented in part at the annual meeting of the Pediatric Academic SocietiesSociety for Pediatric Research, New Orleans, 2 May 1998.

\section{References}

1 Ventura SJ, Martin JA, Curtin SC, Mathews TH. Report of Final Natality Statistics, 1996. National Center for Heal th Statistics: Hyattsville, MD, Monthly vital statistics report; vol 46 no 11 , suppl. 1998.

2 Achenbach TM, Howell CT, Aoki MF, Rauh VA. Nine-year outcome of the Vermont intervention program for low birth weight infants. Pediatrics 1993; 91: 45-55.

3 Carpenter M, Nagell K, Tomasello M. Social cognition, joint attention, and communicative competence from 9 to 15 months of age. Monographs of the Society for Research in Child Development, 1998; 63 (Serial no. 255).

4 Cohen SE. Biosocial factors in early infancy as predictors of competence in adolescents who were born prematurely. J Devel Behav Pediatr 1995; 16: 36-41.

5 Cohen SE, Parmelee AH. Prediction of five-year Stanford-Binet Scores in preterm Infants. Child Devel 1983; 54: 1242-1253.

6 Kang R, Barnard K, Hammond M, Oshio S, Spencer C, Thil bodeaux B, Williams J. Preterm infant follow-up project: A multi-site field experiment of hospital and home intervention programs for mothers and preterm infants. Public Health Nurs 1995; 12: 171-180. 
7 Ostfeld BM, Gibbs ED. Family assessment in early intervention. In: Gibbs ED, Teti DM (eds). Interdisciplinary Assessment of Infants. Paul H. Brookes: Baltimore, MD, 1990.

8 Ramey CT, Bryant DM, Wasik, Sparling ل, Fendt KH, LaVange LM. Infant health and development program for low birth weight, premature infants: program elements, family participation and child intelligence. Pediatrics 1992; 89: 454-465.

9 Resnick M, Armstrong S, Carter RL. Developmental intervention program for high-risk premature infants: Effects on development and parent-infant interactions. J Devel Behav Pediatr 1988; 9: 73-78.

10 Thompson RJ, Goldstein RF, Oehler JM, Gustafson KE, Catlett AT, Brazy J. Developmental outcome of very low birth weight infants as a function of biological risk and psychosocial risk. $J$ Devel Behav Pediatr 1994; 15: 232-238.

11 Bornstein MH, Ruddy MG. Infant attention and maternal stimulation: Prediction of cognitive and linguistic development in singletons and twins. In: Bouma H, Bouhuis DG (eds). Attention and Performance $X$ : Control of Language Lawrence Erlbaum Associates: Hillsdale, NJ, 1984, pp 433-445.

12 Clark PM, Dickman A. Features of interaction in infant twins. Acta Genet Med Gemellol 1984; 33: 165-171.

13 Conway D, Lytton H, Pysh F. Twin-singleton language differences. Can JBehav Sci 1980; 12: 264-271.

14 Lytton H. Parent-Child Interaction: The Socialization Process Observed in Twin and Singleton Families. Plenum: New York, 1980.

15 Robin M, Casati I. Are twins different from singletons during early childhood? Early Devel Parenting 1994; 3: 211-221.

16 Robin M, Dorroyer D, Casati I. Childcare patterns of mothers of twins during the first year. JChild Psychol Psychiatr 1996; 37 : 453-460.

17 Savic S. How Twins Learn to Talk. Academic Press: New York, 1980.

18 Tomasello M, Mannle S, Kruger AC. Linguistic environment of one- to two-year old twins. Devel Psychol 1986; 22: 169-176.

19 Hay DA, O'Brien PJ. The role of parental attitudes in the development of temperament in twins at home, school and in test situations. Acta Genet Med Gemellol 1984; 33: 191-204.

20 Robin $M$, Josse $D$, Tourrete $C$. Forms of family reorganization following the birth of twins. Acta Genet Med Gemellol 1991; 40: 53-61.

21 Thorpe K, Golding J, MacGillivray I, Greenwood R. Comparison of prevalence of depression in mothers of twins and mothers of singletons. Br Med J 1991; 302: 875-878.

22 Field T. Infants of depressed mothers. Devel Psychopathol 1992; 4: 49-66.

23 Goodman G, Aber J, Berlin L, Brooks-Gunn J. Children's internal working models of attachment security. Infant Mental Health J 1998; 19: 378-393.

24 Murray L, Fiori-Cowley A, Hooper R. The impact of postnatal depression and associated adversity on early mother-infant interactions and later infant outcome. Child Devel 1996; 67: 2512-2526.

25 Affleck G, Tennen H, Rowe J. Infants in crisis: How parents cope with newborn intensive care and its aftermath. SpringerVerlag: New York, 1991.

26 Hagan R, Pope S, Priest S, French N, Evans S. Very preterm delivery, maternal depression and outcomes for mother and infant. Pediatr Res 1998; 43: 217A.

27 Mayes LC. The assessment and treatment of the psychiatric needs of medically comprised infants: consultation with preterm infants and their families. Child Psychiatr Clinics $\mathrm{N}$ Am 1995; 4: 550-570.

28 Meyer EC, Garcia Coll CT, Seifer R, Ramos A, Kilis E, Oh W. Psychological distress in mothers of preterm infants. J Devel Behav Pediatr 1995; 16: 412-417.
29 Donovan EF, Ehrenkranz RA, Shankaran S, Stevenson DK, Wright LK, Younes N, Fanaroff A, Korones SB, Stoll B, Tyson J, Bauer CR, Lemons JA, Ott W, Papile L. Outcomes of very low birth weight twins cared for in the National Institute of Child Health and Human Development Neonatal Research Network's intensive care units. Am J Obstetr Gynecol 1998; 179: 742-749.

30 Hack M, Friedman $H$, Fanaroff AA. Outcomes of extremely low birth weight infants. Pediatrics 1996; 98: 931-937.

31 Censullo M. Developmental delay in healthy premature infants at age two years: Implications for early intervention. J Devel Behav Pediatr 1994; 15: 99-104.

32 Hack M, Gaylor G, Klein N, Eiben R, Schatschneider C, Mercuri-Minich N. School-age outcomes in children with birth weights under 750 g. N Engl J Med 1994; 3331: 753-759.

33 McCormick MC, McCarton C, Tonascia J, Brooks-Gunn J. Early educational intervention for very low birth weight infants: Results from the Infant Health and Development Program. J Pediatr 1993; 123: 527-533.

34 Miller CL, Landry SH, Smith KE, Wildin SR, Anderson AE, Swank PR. Developmental change in the neuropsychological functioning of very low birth weight infants. Child Neuropsychol 1995; 1: 224-235.

35 Nurcombe B, Howell DC, Rauh VA, Teti DM, Ruoff P, Brennan J. An intervention program for mothers of low-birthweight infants: Preliminary results. JAm Acad Child Psychiatry 1984; 23: 319-325.

36 O'Shea TM, Klinepeter KL, Goldstein DJ, Jackson BW, Dillard RG. Survival and developmental disability in infants with birth weights of 501-800 grams born between 1979-1994. Pediatrics 1997; 100: 982-986.

37 Singer L, Yamashita T, Lielen L, Collin M, Baley J. A Iongitudinal study of developmental outcome of infants with bronchopulmonary dysplasia with very low birth weight. Pediatrics 1997; 100: 987-993.

38 Greene M, Draft B. How to raise septuplets. Life 1998; 21(6): 39-52.

39 Hollingshead AB. Two-Factor Index of Social Position. Yale University Press: New Haven, CT, 1969.

40 Brazelton TB. Neonatal Behavioral Assessment Scale. Spastics International Medical Publications: London, Philadelphia, Lippincott, 1973.

41 Beckwith L. Instructional manual for assessing infant-caretaker interaction in the home. UCLA Department of Pediatrics, 1973 (unpublished paper).

42 Beckwith L, Cohen SE, Kopp CB, Parmelee AH, March TG. Caregiver-infant interaction and early cognitive development in pre-term infants. Child Devel 1976; 47: 579-587.

43 Bayley N. Bayley Scal es of Infant Development. The Psychological Corporation: New York, 1969.

44 Cal dwell BM, Bradley RH. Home observation for measurement of the environment. University of Arkansas: Little Rock, AK, 1984.

45 Littman B, Parmelee AH. Medical correlates of infant development. Pediatrics 1978; 61: 470-474.

46 Lester BM, Als H, Brazelton TB. Regional obstetric anesthesia and newborn behavior: a re-analysis toward synergistic effects. Child Devel 1982; 53: 687-692.

47 Gross RT, Spiker D, Haynes CW (eds). Helping low birth weight premature babies: The infants' health and development program. Stanford University Press: Stanford, CA, 1997.

48 Siegel LS. Reproductive, perinatal and environmental factors as predictors of the cognitive and language development of preterm and full-term infants. Child Devel 1982; 3: 963-973.

49 Wilson RS. The Louisville twin study: Developmental synchronies in behavior. Child Devel 1983; 54: 298-316.

50 Nielsen HC, Harey-Wilkes K, MacKinnon B, Hung S. Neonatal outcome of very premature infants from multiple and singleton gestations. Am J Obstetr Gynecol 1997; 177: 653-659. 
51 Leonard CH, Piecuch RA, Ballard BA, Cooper B. Outcome of VLBW infants: Multiple gestation vs singletons. Pediatrics 1994; 93: 611-615.

52 Wilson RS. Risk and resilience in early mental development. Develop Psychol 1985; 21: 795-805.

53 Rutter M, Redshaw J. Growing up as a twin: Twin-singleton differences in psychological development. J Child Psychol Psychiatry 1991; 32: 885-895.

54 Vandell DL. Development in twins. Ann Child Devel 1990; 7 : 145-174.

55 Field T, Sandberg D, Garcia R, Vega-Lahr N, Goldstein S, Guy L. Prenatal problems, postpartum depression and early mother-infant interactions. Develop Psychol 1985; 12: $1152-1156$.

56 Goldberg S, DiVitto B. Parenting children born preterm. In: Bornstein MH (ed). Handbook of Parenting, vol 1: Children and Parenting. Lawrence Erlbaum Associates: Mahwah, New Jersey, 1995, pp 209-231.
57 Goldberg S, Perrotta M, Minde K, Corter C. Maternal behavior and attachment in low-birth-weight twins and singletons. Child Devel 1986; 57: 34-46.

58 Lee H, Barratt MS. Cognitive development of preterm low birth weight children at 5 to 8 years old. JDevel Behav Pediatr 1993; 14: 242-249.

59 M sall ME, Buck GM, Rogers BT, Merke D, Catanzaro NL, Zorn WA. Risk factors for major neurodevelopmental impairments and need for special education resources in extremely premature infants. JPediatr 1991; 119: 606-614.

60 Meyer EC, Garcia Coll CT, Lester BN, Zacariah Boukydis CF, McDonough S, Oh W. Family-based intervention improves maternal psychological well-being and feeding interaction of preterm infants. Pediatrics 1994; 93: 241-246. 